\title{
Regional Emerging Diseases Intervention (REDI) Centre
}

\author{
Rodney Hoff*, Ai Li Quake, Za Reed, Rohini Rao, Yeean Leng Kong, Soo Sim Lee, Philippe Cavailler \\ From Institut Pasteur International Network Annual Scientific Meeting \\ Hong Kong. 22-23 November 2010
}

\section{Genesis}

The Regional Emerging Diseases Intervention (REDI) Centre is a research and training organization, founded by Singapore and the United States to enhance the AsiaPacific region's capability and capacity to deal with emerging and reemerging infectious diseases. REDI Centre is chartered in Singapore as a non-profit, intergovernmental Organization.

\section{Missions}

i/ To promote international exchange of information, knowledge and expertise through the organization of scientific conferences, ii/ to act as a regional resource for training and research, iii / to support programs that will strengthen the response and the control to critical health threats, and iv / to improve regional capacity to prevention, surveillance diagnosis and management of Emerging Infectious Diseases (EIDs).

\section{Regional conferences recently organized}

Forum on Hand Foot and Mouth Disease, Chikungunya Symposium and Fourth ASEAN Congress on Tropical Medicine and Parasitology.

\section{Laboratory capacity}

Together with Singapore and international partners (WHO, US-NIH ...), REDI Centre organized several onsite lab training in Singapore public health laboratories as well as regional trainings on laboratory techniques and principles for EIDs diagnosis (biosafety train-thetrainer courses, Influenza PCR and virus isolation and characterization workshops, Asia-Pacific Dengue workshops). REDI collaborated with partners to form a regional network with the aim to improve laboratory EIDs

Regional Emerging Diseases Intervention (REDI) Centre, Singapore Full list of author information is available at the end of the article diagnosis and surveillance (biosafety, quality insurance, development of guidelines for EID diagnosis).

\section{Clinical capacity}

In the area of hospital infection control, REDI Centre actively contributed to the development of state-of-theart training modules and currently assists the $\mathrm{MOHs}$ of Vietnam (implementation of the National Infection Prevention and Control Master Plan), Indonesia (revision of the National Guideline for AI management and infection control) and Cambodia (surveillance of nosocomial infections in Kampong Cham Hospital).Together with Pasteur Network, WHO and other partners, organization of a regional course on Infection Control in Vientiane (with Pasteur Network) and development of clinical guidelines for the clinical management of Hand, Foot and Mouth Disease

\section{Epidemiology capacity}

REDI centre supports Singaporean and Indonesian FETPs and co-organized (with Pasteur Network and National University of Singapore) several short regional courses: "Data-management and Basic Statistics", "Outbreak Investigation". In Indonesia REDI Centre collaborates in the Trilateral Pilot Project on Surveillance and Control of Avian Influenza in Tangerang (with Indonesian Ministries of Health and Agriculture) and in the realization of a study aiming to assess the $\mathrm{H} 5 \mathrm{~N} 1$ seroprevalence in poultry workers and in poultry in live market facilities (with USCDC and NIHRD).

Published: 10 January 2011

doi:10.1186/1753-6561-5-S1-P111

Cite this article as: Hoff et al: Regional Emerging Diseases Intervention (REDI) Centre. BMC Proceedings 2011 5(Suppl 1):P111. 